\title{
Pathways of cervical cancer screening among Chinese women
}

\author{
This article was published in the following Dove Press journal: \\ International Journal of Women's Health \\ 21 June 2013 \\ Number of times this article has been viewed
}

\author{
Grace $X \mathrm{Ma}^{\prime}$ \\ Min Qi Wang ${ }^{2}$ \\ Xiang $\mathrm{S} \mathrm{Ma}^{3}$ \\ Steven E Shive ${ }^{4}$ \\ Yin $\operatorname{Tan}^{5}$ \\ Jamil I Toubbeh ${ }^{5}$ \\ 'Department of Public Health, \\ College of Health Professions, \\ Temple University, Philadelphia, \\ PA, ${ }^{2}$ Department of Public and \\ Community Health, University \\ of Maryland, College Park, MD, \\ ${ }^{3}$ College of Health Professions \\ and School of Medicine, Temple \\ University, Philadelphia, PA, ${ }^{4}$ Center \\ for Asian Health, Temple University, \\ and Department of Health, East \\ Stroudsburg University, East \\ Stroudsburg, PA, ${ }^{5}$ Center for Asian \\ Health, Department of Public Health, \\ College of Health Professions, Temple \\ University, Philadelphia, PA, USA
}

Correspondence: Grace X Ma Department of Public Health, College of Health Professions, Temple University, I30| Cecil B Moore Ave, 913 Ritter Annex, Philadelphia, PA 19122-0843, USA

Tel +I 2157875434

Fax + I 2157875436

Email grace.ma@temple.edu
Background: The purpose of this community-based study was to develop a structural equation model for factors contributing to cervical cancer screening among Chinese American women.

Methods: A cross-sectional design included a sample of 573 Chinese American women aged 18 years and older. The initial step involved use of confirmatory factor analysis, that included the following variables: access to and satisfaction with health care, and enabling and predisposing cultural and health beliefs. Structural equation model analyses were conducted on factors related to cervical cancer screening.

Results: Age, marital status, employment, household income, and having health insurance, but not educational level, were significantly related to cervical screening status. Predisposing and enabling factors were positively associated with cervical cancer screening. The cultural factor was significantly related to the enabling factor or the satisfaction with health care factor.

Conclusion: This model highlights the significance of sociocultural factors in relation to cervical cancer screening. These factors were significant, with cultural, predisposing, enabling, and health belief factors and access to and satisfaction with health care reinforcing the need to assist Chinese American women with poor English fluency in translation and awareness of the importance of cervical cancer screening. Community organizations may play a role in assisting Chinese American women, which could enhance cervical cancer screening rates.

Keywords: Papanicolaou test, cervical cancer screening, Chinese women

\section{Introduction}

Asian American women have the lowest cervical cancer screening rate of all racial groups. ${ }^{1,2}$ The incidence rates of cervical cancer for Chinese American women have ranged from $5.4 / 100,000$ to $12.3 / 100,000$, and mortality rates are approximately $1.5 / 100,000 .{ }^{3,4}$ Chinese American women are one of the least likely groups ( $\left.43 \%-84 \%\right)$ to ever get a Papanicolaou test and the least likely to have had one within the last three years (68\%) compared with other racial/ethnic groups in the US. ${ }^{5,6}$ Papanicolaou screening is recommended for sexually active women, starting within three years of onset of sexual activity; all women over 21 years of age should have an annual test until age 30 years. Beyond this age, women who have had three consecutive satisfactory and normal/negative Papanicolaou tests may be screened every 2-3 years if they do not have: a history of a low-grade squamous intraepithelial lesion, a highgrade squamous intraepithelial lesion, or cervical intraepithelial neoplasia 2 or 3; a compromised immune system; human immunodeficiency virus (HIV) infection; or exposure to diethylstilbestrol in utero. ${ }^{7}$ submit your manuscript $\mid$ www.dovepress.com

Dovepress

http://dx.doi.org// 0.2147/IJWH.S45405
(C) $2013 \mathrm{Ma}$ et al, publisher and licensee Dove Medical Press Ltd. This is an Open Access article which permits unrestricted noncommercial use, provided the original work is properly cited. 
For the general population, having a Papanicolaou test in the past three years has been found to be associated with higher education, higher household income, being able to work, having seen a physician in the past year, and having health insurance. ${ }^{1,8,9}$ Higher cervical cancer incidence and mortality rates are associated with lower socioeconomic status. ${ }^{10-12}$ Low Papanicolaou screening rates are associated with having no contact with a primary care provider in the past year, lack of a usual source of care, low family income, low educational attainment, and being unmarried. ${ }^{13}$ Women who have health insurance and who have seen a physician in the previous year are more likely to have been screened. ${ }^{1,8}$ Approximately twice as many foreign-born women report not having had a Papanicolaou test compared with women born in the US. Common barriers to testing reported among the general population have included fear, embarrassment, cost, transportation, communication barriers, lack of health care provider referral, and lack of time. ${ }^{14,15}$ Some of the reasons that Asian American women have been hindered from getting a Papanicolaou test include access, communication, and embarrassment, as well as marital status, sexual behavior, perceived risk, and sex of the health care provider. ${ }^{14,16-18}$ Unmarried Chinese American women tend to be less sexually active than unmarried US-born women, have low perceptions of risk due to little family history and less sexual activity, are embarrassed about getting a vaginal examination, prefer women as examiners, will not get screened if no women are available, and have less access to health care due to language barriers and low literacy levels. ${ }^{14,19}$

The sociocultural health behavior model stresses the interrelationships between individual, interpersonal, and environmental factors. This model examines relationships between individual health behavior and interaction with the environment. The interactions and multiple levels of influence of individual, interpersonal, and environmental factors underlying health behavior are emphasized in an ecological model.

Structural equation modeling has been used in studies related to health problems such as minority youth substance use, HIV risk reduction interventions for injectable drug users under treatment, stress reduction, racial/ethnic disparities in knowledge of HIV testing and treatment, and other problems. ${ }^{20-23} \mathrm{~A}$ few studies have used structural equation modeling in examining cancer-related behaviors or outcomes such as cancer survivorship, communication between medical staff and families of cancer patients, and intention to obtain genetic tests for colon cancer. ${ }^{24-26}$ Structural equation modeling offers some advantages in examining research questions based on theories such as the ecological model. ${ }^{27}$ The structure of relationships among a set of factors can be tested, ${ }^{28}$ there is increased statistical control over random measurement error and measurement biases, ${ }^{27}$ and examination of interrelated constructs can occur without the disadvantages of a multivariate analysis of covariance approach. ${ }^{29}$ Given that screening behavior is influenced by multiple factors, there is a need to identify these interrelationships and the pathways among these factors. The role of cultural factors is seldom included in health behavior analysis.

Figure 1 shows the sociocultural health behavior model ${ }^{30}$ when used to explain health behavior. In addition to common theoretical components, this model includes cultural factors as a primary component. The model incorporates the

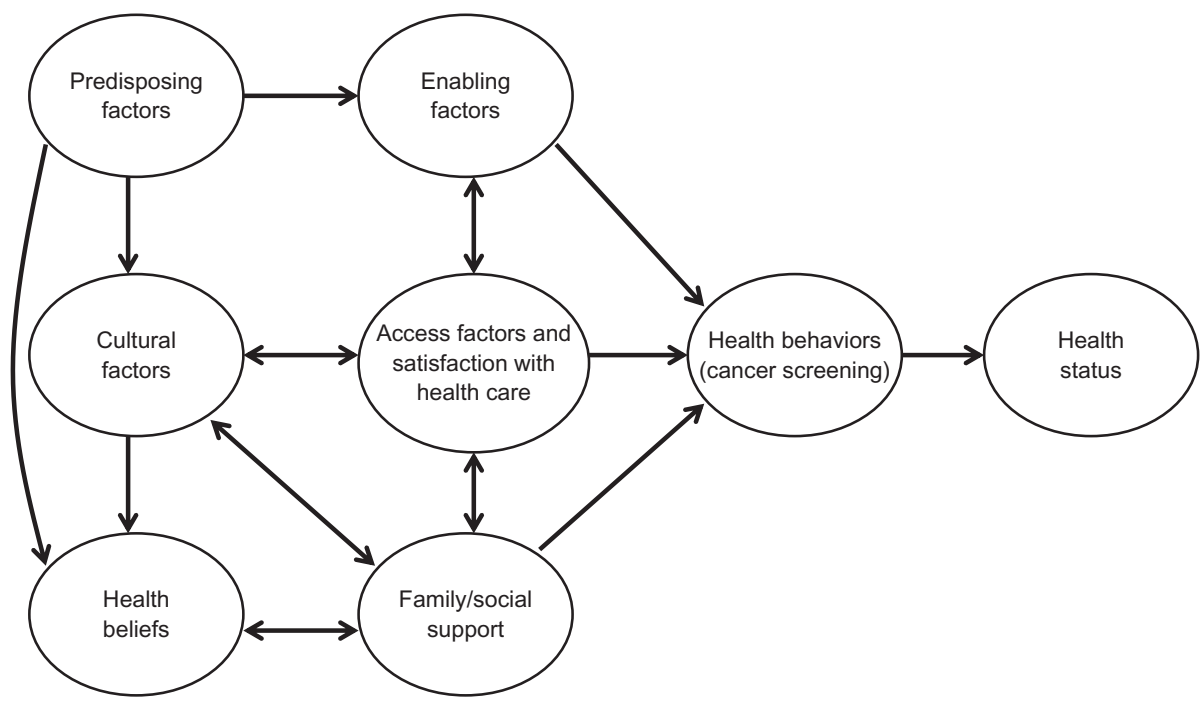

Figure I Structural equation model of socio-cultural health behavior constructs in relation to the health service utilization. 
interdependence of predisposing, enabling, need, family/ social support, environmental health systems, and cultural factors which contribute to a particular health behavior or outcome. A number of variables can be included under cultural factors, including notions of fatalism, birth in the US, years lived in the US, level of English fluency, use of a native language at home, native food eaten and at what frequency, use of media sources in a native language, and attendance at native social events.

The purpose of this community-based study was to validate a proposed sociocultural health behavior model by using structural equation analysis to determine the direction and magnitude of the interdependence of the proposed components of the model in relation to the health behavior of cervical cancer screening among Chinese American women.

\section{Materials and methods}

\section{Sample}

This study was part of a larger study which included a sample of Chinese, Korean, Vietnamese, and Cambodian Asian Americans selected by obtaining a current list of 111 Asian American community organizations in the greater Philadelphia area, New Jersey, and New York City, which were identified by the Asian Community Cancer Coalition and staff of the Asian Community Cancer Network (ATECAR). These organizations are located in geographic areas which helped to maximize the coverage of Asian Americans across ethnic groups, age, and socioeconomic status. Asian American community organizations $(n=52)$ were randomly selected as clusters from the list of 111 organizations. The selected community organizations were stratified based on the four racial/ ethnic or language groups. A proportional allocation procedure of assigning the sample size proportionally to subgroup size was used. ${ }^{31}$ Of the 2098 women who agreed to participate, 2011 completed the study, giving a response rate of $95.9 \%$. The overall sample consisted of 2011 participants, including: Chinese, 45.9\% $(\mathrm{n}=923)$; Korean, 19.1\% $(\mathrm{n}=384)$, Vietnamese, $18.1 \%(\mathrm{n}=364)$, and Cambodian, $16.9 \%(n=340)$. Cambodian organizations were oversampled in order to ensure that this population subgroup was adequately represented in the data. After selecting Chinese American women aged 18 years and older and excluding missing data, the final sample for this study consisted of 573 women.

\section{Design and data collection procedures}

A cross-sectional research design was used because of the common advantages provided by this method, such as collecting information from numerous diversified participants in a short time period. Data were collected at the facilities of the Asian American community organizations. Training in data collection was provided to all survey administrators as well as to onsite bilingual translators. The survey was administered using one-on-one and face-to-face instruction methods. Language assistance was provided during administration of the survey. Participants had the option of responding to the questionnaire in English or in their native language (Chinese, Korean, or Vietnamese). Translators were provided when needed for individual or group translations.

\section{Measurements}

A multilingual questionnaire was developed by the principal investigator and the research team. The 95-item questionnaire was back-translated and pilot-tested for reliability, validity, and cultural appropriateness with community partners. The average time taken to complete the questionnaire was 25 minutes.

The initial step involved use of confirmatory factor analysis, which included the following variables: access factors/satisfaction with health care (physician language concordance, insurance covering screening, physician advice to get screened, assistance in transportation, access to medical services when needed, arrangements with appointments, length of time waiting to see physician, ability to contact physician after hours or weekends, convenience of location of physician, and quality of care by the physician); enabling factors (annual household income, having health insurance, coverage of screening by an insurance provider, having a primary care physician, and barriers to screening, such as language, transportation, lack of knowledge about disease or location of services, having routine health exams, and self-efficacy); predisposing factors (age, sex, marital status, education level, ethnic background, and employment status); cultural factors (fatalism, importance of screening, birth in the US, years lived in the US, ability to speak English, use of a native language at home, preparation of a native food at home, and use of media sources in a native language); health beliefs (feeling well so there were no perceived health problems, susceptibility, fear of getting a bad test result, embarrassment/shame of getting the test, and fear of having a health problem); and family/social support (family support of screening, acting on physician's advice, and family or friends having breast cancer).

The survey questionnaire items used in the structural equation modeling analysis are described as follows. 


\section{Access to and satisfaction with health care}

Seven items assessed respondents' perceptions of their health care and doctors' services. The response categories were on a five-choice scale, ie, "poor", "fair", "good", "very good", and "excellent".

\section{Enabling factor}

The enabling factor was measured using three questions: Do you currently have health insurance? Do you have a primary health care provider to go to when you are sick? How many times did you visit your current primary physician in the last 12 months? The response categories were a binary choice (no/yes) for the first two questions. The third question's answer choices were on an ordinal scale with four choices, ie, "never", "1-2 times", "3-4 times", and "5 or more times."

\section{Predisposing factor}

The predisposing factor measured the education level of the participants, including their highest grade of school completed and their years of education completed.

\section{Cultural factor}

The cultural factor included participants' English proficiency and their level of information-seeking (Internet use). The response categories were "not at all" to "very well" for English speaking and a binary choice (no/yes) for Internet use.

\section{Health belief factor}

The cancer fear factor reflects the fear of knowing a bad cancer test result and whether the participants felt embarrassment about cancer. The response categories were a binary choice (no/yes).

\section{Statistical analysis}

Latent model analyses were conducted using Mplus software (Muthén \& Muthén, Los Angeles, CA, USA). ${ }^{32}$ The models were covariance structural models with multiple indicators for all latent constructs. The analysis entailed a two-step procedure using maximum likelihood estimation. The first step was confirmatory factor analysis to test the measurement model. A measurement model describes the nature of the relationship between a number of latent variables and the observed variables corresponding to each of the constructs. The second step tested the structural model, as shown in Figure 1. This step represents the theoretically based model in which the relationships between exogenous variables (those variables with both emanating paths and receiving paths) and endogenous variables (those variables with mostly receiving paths) can be seen. The dependent factor is a binary variable, ie, never screened versus screened. Using ordinal and dichotomous indicators is a very common practice in the structural equation modeling literature. This practice is based on the assumption that the underlying construct represented by the dichotomous variables is continuous. A tetrachoric correlation was created instead of the Pearson correlation for the structural equation modeling analysis. ${ }^{32}$

Multiple indices were used to test the model fit, and included the following: comparative fit indices, where a value $\geq 0.90$ is considered acceptable; ${ }^{28}$ the Tucker-Lewis Index, where a value $\geq 0.90$ is considered acceptable, ${ }^{28}$ and the root mean square error of approximation, ${ }^{33,34}$ with the value $<0.08$ indicating a good fit.

\section{Results}

\section{Sample characteristics}

The relationship between the demographic and mammogram screening status is presented in Table 1. Age was significantly related to screening status $\left[\chi^{2}(4)=36.30\right.$, $P<0.01]$. Younger women (aged 18-39 years) were more likely to be never-screened (46.8\%) than women in the 40-64-year age group (20.6\%) and the 65+ age group (19.7\%). Marital status was significantly related to screening status $\left[\chi^{2}(2)=34.94, P<0.01\right]$. More unmarried women than married women reported being never-screened (47.1\% versus $22.4 \%$ ). More unemployed women (37.6\%)

Table I Demographic and mammogram screening status

\begin{tabular}{|c|c|c|c|}
\hline$n=573$ & $\begin{array}{l}\text { Never } \\
\text { screened (\%) }\end{array}$ & $\begin{array}{l}\text { Noncompliance } \\
\text { (\%) }\end{array}$ & $\begin{array}{l}\text { Compliance } \\
\text { (\%) }\end{array}$ \\
\hline \multicolumn{4}{|l|}{ Age category* } \\
\hline 18-39 years & 46.8 & 12.9 & 40.3 \\
\hline $40-64$ years & 20.6 & 21.8 & 57.5 \\
\hline $65+$ years & 19.7 & 23.4 & 56.9 \\
\hline \multicolumn{4}{|c|}{ Current marital status* } \\
\hline Unmarried & 47.1 & 24.0 & 28.9 \\
\hline Married & 22.4 & 20.7 & 56.9 \\
\hline \multicolumn{4}{|l|}{ Highest degree } \\
\hline$<$ High school & 33.3 & 18.5 & 48.1 \\
\hline$>$ High school & 26.6 & 22.5 & 50.8 \\
\hline \multicolumn{4}{|c|}{ Employment status* } \\
\hline Employed & 22.5 & 21.3 & 56.2 \\
\hline Unemployed & 37.6 & 22.2 & 40.2 \\
\hline \multicolumn{4}{|c|}{ Annual income* } \\
\hline$<\$ 10,000$ & 39.8 & 14.4 & 45.9 \\
\hline$\$ 10,000-\$ 30,000$ & 22.5 & 24.6 & 52.9 \\
\hline$>\$ 30,000$ & 11.8 & 24.7 & 63.4 \\
\hline \multicolumn{4}{|c|}{ Current health insurance* } \\
\hline No & 48.1 & 24.0 & 27.9 \\
\hline Yes & 21.1 & 20.6 & 58.3 \\
\hline
\end{tabular}

Note: $* P<0.01$, Chi-square test. 
reported being never-screened than employed women $(22.5 \%)\left[\chi^{2}(2)=15.71, P<0.01\right]$. Screening status was associated with annual household income $\left[\chi^{2}(4)=29.54\right.$, $P<0.01]$. Of women with an annual household income of less than $\$ 10,000,39.8 \%$ reported being never-screened compared with $11.8 \%$ of women with an annual household income of more than $\$ 30,000$. Health insurance status was significantly related to screening status $\left[\chi^{2}(2)=43.55\right.$, $P<0.01]$. The percentage of women without health insurance who reported being never-screened was more than double that of women with health insurance (48.1\% versus $21.1 \%$ ). Education was not significantly related to screening status.

\section{Model fit index}

The comparative fit index for the structural equation modeling model was 0.919 , which meets the acceptable model fit criterion. The Tucker-Lewis Index yielded a value of 0.945 . The root mean square error of approximation compares the observed variances and covariances with those resulting from the model's parameter estimates and is not sensitive to sample size. A root mean square error of approximation of 0.071 indicated acceptable fit of the measurement model.

\section{Measurement model}

The factor loadings for the indicator variables associated with the constructs are shown in Table 2. The factor loadings are equivalent to standardized regression weights for predicting observed variables from latent constructs. The $t$ scores obtained for the coefficients in Table 2 were all significant except for one variable (embarrassment/shame). The magnitude of the factor loadings and their significance provided evidence to support the convergent validity of the indicators. Overall, the model fit indices and the factor loadings supported the reliability and validity of the constructs for their indicator variables. It was concluded that the theoretical constructs hypothesized to exist at the level of latent factors were assessed with an acceptable degree of precision and that the observed variables were adequate indicators of these factors.

\section{Structural model}

The hypothesized model and the standardized maximum likelihood estimates for the parameters of the model are shown in Figure 2. For all figures presented in this section, the constructs were coded in the same direction, ie, a positive path coefficient indicates a greater likelihood of being associated with cancer screening.
Table 2 Parameter estimates for the hypothesized measurement model

\begin{tabular}{ll}
\hline Construct and indicators $\mathbf{n}=\mathbf{5 7 3}$ & $\begin{array}{l}\text { Factor } \\
\text { loading }\end{array}$ \\
\hline Access factors/satisfaction with health care & \\
Arrangements for making appointments for medical care & 1.000 \\
Length of time waiting to see doctor at the office & 0.935 \\
Length of time between making an appointment & 0.908 \\
for care and visit & \\
Overall rating of medical group care & 0.862 \\
Convenience of location of the doctor's office & 0.946 \\
Access to medical care whenever needed & 0.920 \\
Quality of care from your physician & 0.770 \\
Enabling factor & \\
Currently have health insurance & 1.00 \\
Have a primary health care provider to go to when sick & 1.050 \\
$\quad$ Number of visits to primary physician in the & 0.642 \\
previous I2 months & \\
Predisposing factor & \\
$\quad$ Highest grade of school completed & 1.00 \\
Years of education completed & 3.952 \\
Cultural factor & \\
Using Internet for sources of information & 1.00 \\
Perceived English proficiency & 0.852 \\
Speaking native Asian language at home & 0.372 \\
Health belief factor & \\
Fear of a bad test result & 1.00 \\
Embarrassment/shame & 1.664 \\
\hline
\end{tabular}

The path coefficients indicate the direction and magnitude of the associations. The enabling factor showed a positive and significant relationship with the screening factor (coefficient $=0.474, t=6.817, P<0.001$ ) . The predisposing factor also indicated a positive and significant relationship with the screening factor (coefficient $=0.176, t=2.711$, $P<0.01$ ). These two significant path coefficients indicate that women with health insurance, a primary health care provider, and frequent primary physician visits were more likely to have had cervical cancer screening; and more educated women were also more likely to have been screened. The cultural factor was not directly related to cancer screening. However, it was significantly related to the enabling factor as well as the satisfaction with health care factor. Although the satisfaction with health care factor was positively related to cancer screening, it was not significant $(P>0.05)$. The $\mathrm{R}^{2}$ value explained the variance between the construct variables. Overall, $23 \%$ of the cancer screening was explained by the constructs of the model.

\section{Discussion}

The present study evaluated the relationship between cervical cancer screening and factors in the sociocultural health 


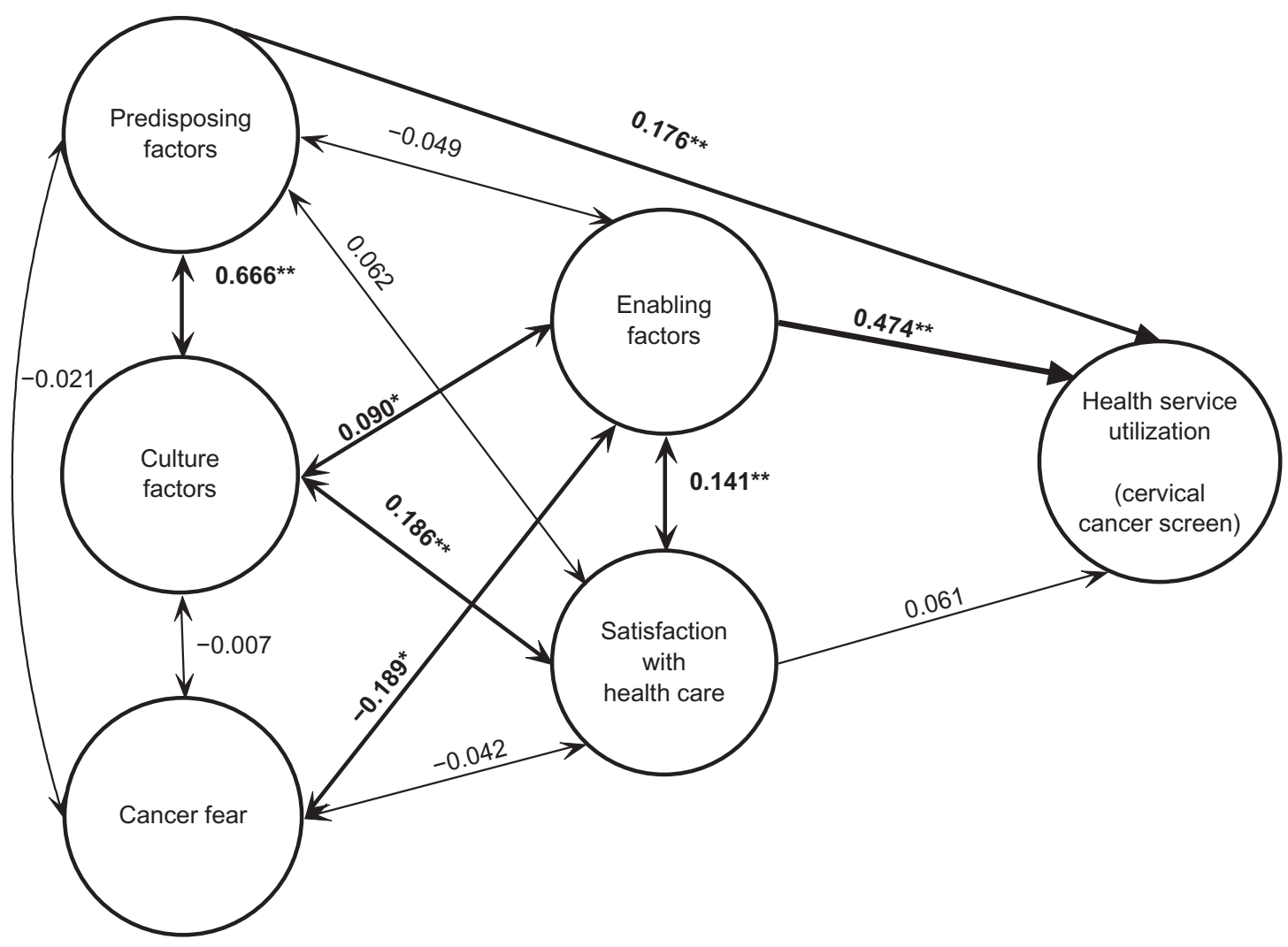

Figure 2 Path coefficients and their significance from the structural equation modeling analysis.

Notes: Comparative Fit Indices $=0.919$; Tucker-Lewis Index $=0.945 ;$ RMSEA $=0.07 \mathrm{I} . \mathrm{n}=573$. Unstandardized estimates are shown. Cervical cancer screen is coded I $=$ no, $2=$ yes. $* * P<0.01 ; * P<0.05$. Bold lines indicate $P<0.05$.

behavior model. We used structural equation model analysis to determine the structural relationship and multiple levels of influence of predisposing, enabling, cultural, environmental health system, and family/social support factors underlying cervical cancer screening in Chinese American women. The study results demonstrate some significant pathways of the original model proposed and some additional factors.

Age, marital status, employment status, annual income, and health insurance status were significantly related to cervical cancer screening. Women who were younger, unmarried, unemployed, with a low annual income, and without health insurance were more likely to be never-screened and noncompliant with cervical cancer screening than those who were older, married, and employed, with a higher income and health insurance. Studies consistently show that lack of health insurance leads to reduced screening. ${ }^{5,8,35-39}$ Having health insurance is a primary enabling factor, especially given the cost of medical services. While not statistically significant, Chinese American women with higher annual incomes and education levels were more likely to be screened than those with lower incomes and education levels. The role of education has not been examined systematically in published studies. Some studies show support for the direct and indirect influences of educational level on cancer screening, while analyses in other studies have not shown a significant correlation between educational level and socioeconomic status in cancer screening. ${ }^{40-42}$ A possible explanation is that the constructs of education and income are multidimensional. Future research of this issue may need to explore education, income level, and socioeconomic status separately to assess whether these variables are significantly related to cervical cancer screening. Further, low income may not be as important to cervical cancer screening because some Chinese American women who had Medicaid/Medicare, and therefore were eligible to obtain cervical cancer screening regardless of their income level.

\section{Structural equation modeling}

Overall, our results offer support for a multilevel sociocultural approach to understanding the relationship between access/satisfaction with health care, predisposing, enabling, and cultural factors, health beliefs, and cervical cancer screening. Factor loadings were significant for the enabling and predisposing factors and showed a positive and significant relationship with screening for cervical cancer. Chinese American women with health insurance, a primary care 
provider they saw frequently, access to and satisfied with their health care, and proficiency in English, and who were not afraid of a bad screening result or embarrassed about the test were more likely to be screened for cervical cancer than those who did not have these characteristics.

The findings from the path coefficients also lend support for components of the sociocultural model and indicate that there is a positive and significant relationship between cervical cancer screening and the predisposing factor (coefficient $=0.176)$ and enabling factor $($ coefficient $=0.474)$, indicating that women with higher scores for predisposing and enabling were more likely to seek cervical cancer screening. A significant relationship was also found between cultural factors and predisposing, enabling, and access to and satisfaction with health care factors, and between enabling factors and access to a satisfaction with health care and health belief factors. In general, if Chinese American women were able to access and were satisfied with health care, they were more likely to have a Papanicolaou test.

There were a number of factors which were loaded heavily under access to and satisfaction with health care. These factors included being able to make an appointment, not having to wait long, having providers in a convenient location, and rating providers highly. The cultural factor was significantly related to predisposing and enabling factors and satisfaction with health care. Chinese American women who perceived that they were fluent in English and who used the Internet as a source of information were more likely to have a Papanicolaou test. A health belief, ie, that of fearing a bad test result, was also determined to be a factor in whether women went for cervical cancer screening and was correlated with enabling factors. The model accounted for $23 \%$ of the variance in cervical cancer screening.

The model highlights the significance that sociocultural factors play in relation to cervical cancer screening and was significant for predisposing, enabling, and access to and satisfaction with health care factors. Predisposing and enabling factors were related to cervical cancer screening. Women in the lower socioeconomic status categories and those with lower educational levels are likely to have higher mortality rates and be diagnosed with late-stage cervical cancer. ${ }^{11}$ Other studies show that while Asians of lower socioeconomic status and those with less education are less likely to have Papanicolaou testing, Asian women had lower screening rates than white women even if they had more education and the screening rates varied by ethnic subgroup. ${ }^{43,44}$ This suggests that there may be other cultural factors influencing screening rates. Consistent with previous studies, being more acculturated in the US in general, and the ability to speak English, in particular, is associated with higher cervical cancer screening rates among Chinese Americans. ${ }^{14}$ These findings reinforce the necessity to assist Chinese American women, who have poor English language skills, with translation and awareness of the importance of Papanicolaou testing.

In conclusion, this study analyzed and illustrated a model of the pathways among constructs leading to cervical cancer screening among Chinese American women. By using structural equation modeling, the most likely linkages between constructs and mediating factors can be examined. This model investigated how cultural, predisposing, enabling, access/satisfaction with health care, and health belief factors relate to cervical cancer screening. To our knowledge, the present study is one of the first to perform a path analysis with regard to factors that may lead to cervical cancer screening.

\section{Limitations}

There are several limitations to this study. First, because the study was cross-sectional, the causality of relationships between the constructs cannot be determined. Second, these findings are based on self-report questionnaires, so may include participant response bias. Third, given that the sample was drawn from Chinese American women belonging to community organizations, the findings may not be generalizable to all Chinese American women.

Prevention efforts must focus on groups with the lowest rates of screening for cervical cancer. To be successful, cervical cancer screening programs should include activities that take into account the multiple interacting factors leading to lower rates of screening among Chinese American women compared with other groups. Sensitivity to ethnic and cultural factors, such as use of English as well as other family or community contexts and dynamics, should be built into all secondary prevention activities, especially the provision of translation services and education materials in native languages to enhance interventions which target improved cervical cancer screening rates among Chinese American women. Furthermore, the significant relationship between cultural factors and more proximal constructs suggests that use of culturally appropriate materials should be explored. Community organizations, which served as the basis for this study, can play a role in assisting Chinese American women to identify, plan, and adopt effective evidence-based screening programs. Such community organizations may work in collaboration with representatives from local government, the local health department, and other related partners to 
achieve greater success than the work of a single agency in implementing prevention programs.

\section{Acknowledgments}

The authors wish to thank the Asian Community Health Coalition partners, volunteers, community coordinators, and research team at the Center for Asian Health, Temple University, who facilitated and supported the completion of this study. Our research was partially supported by grants of the National Institutes of Health (UO1 CA114582, Principle Investigator: Dr Grace Ma) and (U54 CA153513, Principal Investigator: Dr Grace Ma).

\section{Disclosure}

The authors report no conflicts of interest in this work.

\section{References}

1. American Cancer Society. Cancer Prevention and Early Detection Facts and Figures 2006. Atlanta, GA: American Cancer Society; 2006.

2. Lee HY, Ju E, Vang PD, Lundquist M. Breast and cervical cancer screening among Asian American women and Latinas: does race/ ethnicity matter? J Womens Health. 2010;19:1877-1884.

3. Ralston JD, Taylor VM, Yasui Y, Kuniyuki A, Jackson JC, Tu S. Knowledge of cervical cancer risk factors among Chinese immigrants in Seattle. J Community Health. 2003;28:41-57.

4. McCracken M, Olsen M, Chen MS, et al. Cancer incidence, mortality, and associated risk factors among Asian Americans of Chinese, Filipino, Vietnamese, Korean, and Japanese ethnicities. CA Cancer J Clin. 2007;57:190-205.

5. New York City Department of Health and Mental Hygiene. Cervical cancer screening in New York City. Available from: http://www.nyc. gov/html/doh/downloads/pdf/survey/survey-2006cervicalcancer.pdf. Accessed May 11, 2013.

6. Lee-Lin F, Menon U, Pett M, Nail L, Lee S, Mooney K. Breast cancer beliefs and mammography screening practices among Chinese American immigrants. J Obstet Gynecol Neonatal Nurs. 2007;36:212-221.

7. US Department of Health and Human Services (2007). National Guideline Clearinghouse. Available from: http://guideline.gov/syntheses/ synthesis.aspx?id $=43606 \&$ search $=$ Screening + for + cancer. Accessed May 28, 2013.

8. Coughlin SS, Uhler R. Breast and cervical cancer screening practices among Asian and Pacific Islander women in the United States, 1994-1997. Cancer Epidemiol Biomarkers Prevent. 2000;9: 597-603.

9. Downs LS, Smith JS, Scarinci I, Flowers L, Parham G. The disparity of cervical cancer in diverse populations. Gynecol Oncol. 2008;109: S22-S30.

10. Parikh S, Brennan P, Boffeta P. Meta-analysis of social inequality and the risk of cervical cancer. Int J Cancer. 2003;105:687-691.

11. Singh GK, Miller BA, Hankey BF, Edwards BK. Persistent area socioeconomic disparities in US incidence of cervical cancer, mortality, stage, and survival, 1975-2000. Cancer. 2004;101:1051-1057.

12. Singh GK, Azuine RE, Siahpush M. Global inequalities in cervical cancer incidence and mortality are linked to deprivation, low socioeconomic status, and human development. Int J MCH AIDS. 2012;1:17-30.

13. Hewitt M, Devesa SS, Breen N. Cervical cancer screening among US women: analyses of the 2000 National Health Interview Survey. Prev Med. 2004;39:270-278.

14. Hou S, Lessick M. Cervical cancer screening among Chinese women. AWHONN Lifelines. 2002;6:349-354.
15. Yabroff KR. Interventions to improve cancer screening, commentary from a health services research perspective. Am J Prev Med. 2008; 35(Suppl 1):S6-S9.

16. Ji CS, Chen M, Sun J, Liang W. Cultural views, English proficiency and regular cervical cancer screening among older Chinese American women. Womens Health Issues. 2010;20:272-278.

17. Wang JH, Sheppard VB, Schwartz MD, Liang W, Mandelblatt JS. Disparities in cervical cancer screening between Asian American and non-Hispanic white women. Cancer Epidemiol Biomarkers Prev. 2008;17:1968-1973.

18. Tung WC, Nguyen DHT, Tran DN. Applying the transtheoretical model to cervical cancer screening in Vietnamese-American women. Int Nurs Rev. 2008;55:73-80.

19. Woo JST, Brotto LA, Gorzalka BB. The role of sexuality in cervical cancer screening among Chinese women. Health Psychol. 2009;28: 598-604.

20. Copenhaver MM, Lee IC. Optimizing a community-friendly HIV risk reduction intervention for injection drug users in treatment: a structural equation modeling approach. J Urban Health. 2006;83:1132-1142.

21. Ebrahim SH, Anderson JE, Weidle P, Purcell DW. Race/ethnic disparities in HIV testing and knowledge about treatment for HIV/AIDS: United States, 2001. AIDS Patient Care STDS. 2004;18:27-33.

22. Gelderen BV, Heuven E, Veldhoven MV, Zeelenberg M, Croon M. Psychological strain and emotional labor among police-officers: a diary study. J Vocat Behav. 2007;71:446-459.

23. Wang MQ, Matthew RF, Bellamy N, James S. A structural model of the substance use pathways among minority youth. Am J Health Behav. 2005:29:531-541.

24. Bunn JY, Bosompra K, Ashikaga T, Flynn BS, Worden JK. Factors influencing intention to obtain a genetic test for colon cancer risk: a population-based study. Prev Med. 2002;34:567-577.

25. Loitman J, Leeman JM. Testing a mediational model of communication among medical staff and families of cancer patients. Struct Equ Modeling. 2005;12:454-470.

26. Recklitis C, Parsons SK, Mei-Chiung S, Mertens A, Robison L, Zeltzer L. Factor structure of the Brief Symptom Inventory-18 in adult survivors of childhood cancer: results from the childhood cancer survivor study. Psychol Assess. 2006;18:22-32.

27. Bentler PM. EQS Structual Equations Program Manual. Encino, CA: Multivariate Software Inc; 1995.

28. Joreskog KG. Testing structural equation models. In: Bollen KAL, editor. Testing Structural Equation Models. Thousand Oaks, CA: Sage Publications; 1993.

29. Spoth R, Redmond C, Shin C. Direct and indirect latent-variable parenting outcomes of two universal family-focused preventive interventions: extending a public health-oriented research base. J Consult Clin Psychol. 1998;66:385-399.

30. Ma GX, Shive SE, Gao W, Tan Y, Wang MQ. Prostate cancer screening among Chinese American men: a structural model. Am J Health Behav. 2012;36:495-504.

31. Sudman S, Bradburn NM. Asking Questions. San Francisco, CA: Jossey; 1986.

32. Muthén B, Muthén L. Mplus User's Guide. 2000. Available from: http:// www.statmodel.com/ugexcerpts.shtml. Accessed May 11, 2013.

33. Hu LT, Bentler PM. Evaluating model fit. In: Hoyle RH, editor. Structural Equation Modeling: Concepts, Issues, and Applications. Thousand Oaks, CA: Sage; 1995.

34. Kline RB. Principles and Practice of Structural Equation Modeling, 2nd ed. New York, NY: Guilford Press; 2005.

35. Juon HS, Kim M, Shankar S, Han W. Predictors of adherence to screening mammography among Korean American women. Prev Med. 2004;39:474-481.

36. Secginli S, Nahcivan N. Factors associated with breast cancer screening behaviors in a sample of Turkish women: a questionnaire survey. Int $J$ Nurs Stud. 2006;46:161-171. 
37. Tang TS, Solomon LJ, McCracken LM. Cultural barriers to mammography, clinical breast exam, and breast self-exam among Chinese-American women 60 and older. Prev Med. 2000;31: 575-583.

38. Ward E, Jemal A, Cokkinides V, et al. Cancer disparities by race/ethnicity and socioeconomic status. CA Cancer J Clin. 2004;54:78-93.

39. Lim J. Linguistic and ethnic disparities in breast and cervical cancer screening and health risk behaviors among Latina and Asian American women. J Womens Health. 2010;19:1097-1107.

40. Lovejoy NC, Jenkins C, Wu T, Shankland S, Wilson C. Developing a breast cancer screening program for Chinese-American women. Oncol Nurs Forum. 1989;16:181-187.
41. Yi JK, Prows SL. Breast cancer screening practices among Cambodian women in Houston, Texas. J Cancer Educ. 1996;11:221-225.

42. Yu E, Kim KK, Chen EH, Brintnall RA. Breast and cervical cancer screening among Chinese American women. Cancer Pract. 2001;9: 81-91.

43. Kagawa-Singer M, Nadereh P. Asian American and Pacific Islander breast and cervical carcinoma screening rates and Healthy People 2000 objectives. Cancer. 2000;89:696-705.

44. Tsui J, Tanjasiri SP. Cervical cancer screening among Thai women in northern California. J Womens Health. 2008;17:393-401.
International Journal of Women's Health

\section{Publish your work in this journal}

The International Journal of Women's Health is an international, peerreviewed open-access journal publishing original research, reports, editorials, reviews and commentaries on all aspects of women's healthcare including gynecology, obstetrics, and breast cancer. The manuscript management system is completely online and includes

\section{Dovepress}

a very quick and fair peer-review system, which is all easy to use. Visit http://www.dovepress.com/testimonials.php to read real quotes from published authors.

\footnotetext{
Submit your manuscript here: http://www.dovepress.com/international-journal-of-womens-health-journal
} 